\title{
Differences in intermediary energy metabolism between juvenile and adult Fasciola hepatica
}

\author{
Aloysius G.M. Tielens, Josephus M. van den Heuvel and Simon G. van den Bergh \\ Laboratory of Veterinary Biochemistry, State University of Utrecht, Utrecht, The Netherlands
}

(Received 23 January 1987; accepted 27 March 1987)

\begin{abstract}
A comparison of glucose catabolism by juvenile and adult liver flukes, Fasciola hepatica, showed that in the adult the cytosolic degradation of glucose via phosphoenolpyruvate carboxykinase (PEPCK) was the most important route, whereas in the freshly excysted juvenile a large part was degraded via pyruvate kinase (PK). However, it was also shown that the adult did not exclusively use the PEPCK pathway, nor did the juvenile exclusively use the PK pathway. When the juvenile was forced to anaerobic functioning it produced propionate and acetate just like the adult, but this did not imply that it switched to the pathways of the adult: the pathway via PK remained important. Malic enzyme (NADP(H)-dependent) was demonstrated to be present in the cytosol and in the mitochondria of both juveniles and adults. These enzyme activities enable the parasite to use a mixture of malate and pyruvate in any ratio as substrate for the mitochondrial production of propionate and acetate. Pyruvate dismutation was important in the anaerobically functioning juvenile, whereas in the adult malate was the major, but not the only mitochondrial substrate. The pH profiles of PK and PEPCK showed that the pathway of PEP metabolism at the PK/PEPCK branchpoint can be regulated by the pH. However, the end products of glucose breakdown were not dependent on the pH. During its development, the liver fluke will gradually be forced to anaerobic functioning. At first, the acidic end product will favour a partitioning of PEP at the PK/PEPCK branchpoint towards malate formation. Later, a lasting predominance of the PEPCK pathway occurs as PK activity almost completely disappears. During the development of $F$. hepatica also a transition in the mitochondria occurs: at the acetyl-coenzyme A branchpoint a switch from citrate to acetate formation could be demonstrated. The most likely mechanism of this change is discussed.
\end{abstract}

Key words: Fasciola hepatica; Energy metabolism; Glucose breakdown; Aerobic-anaerobic switch; Acetate formation

\section{Introduction}

The energy metabolism of the liver fluke, Fasciola hepatica, changes gradually from aerobic to anaerobic during its development in the vertebrate host [1].

Under aerobic conditions the freshly excysted juvenile degrades glucose to carbon dioxide, whereas it produces propionate and acetate during anaerobiosis $[2,3]$.

Correspondence address: Dr. A.G.M. Tielens, Lab. Vet. Biochem., P.O.Box 80177, 3508 TD Utrecht, The Netherlands.

Abbreviations: MES, ( $N$-morpholino)ethanesulfonic acid; TES, $\quad N$-tris(hydroxymethyl)-methyl-2-aminoethanesulfonic acid; PEP, phosphoenolpyruvate; AcCoA, acetyl-coenzyme A; PEPCK, phosphoenolpyruvate carboxykinase; $\mathrm{MDH}$, malate dehydrogenase; $\mathrm{PK}$, pyruvate kinase; $\mathrm{ME}$, malic enzyme; LDH, lactate dehydrogenase; $\mathrm{FH}$, fumarate hydratase.
On the other hand, the main end products of glucose breakdown by the adult liver fluke are propionate and acetate, both under aerobic and anaerobic conditions $[4,5]$.

The transition from aerobic to anaerobic energy metabolism in the developing liver fluke is probably directly related to its increase in thickness, which results in a decrease in oxygen diffusion to the more inner-laying tissues of the fluke [1]. The accompanying changes in glucose catabolism are unknown and were, therefore, further investigated.

It has been suggested [2] that the cytosolic pathway of glucose breakdown in the juvenile proceeds from phosphoenolpyruvate (PEP) via pyruvate kinase (PK; EC 2.7.1.40) to pyruvate. Although low activities of PK are found in adult liver flukes [6,7], PEP is supposed to be converted into malate via phosphoenolpyruvate car- 
boxykinase (PEPCK; EC 4.1.1.32) by the adult worm. This difference between juveniles and adults was studied.

Glucose breakdown to pyruvate was indeed found to be more important in the juvenile than in the adult. Therefore, a transition from PK to PEPCK activity will have to occur during the development of the liver fluke. Such a switch at the PEP branchpoint is established for the recurring aerobic-anaerobic transitions in bivalve molluscs, in which it is suggested that the $\mathrm{pH}$ is one of the factors involved in the PK-PEPCK switch [8]. In these shell-fishes acidification of the micro-environment by anaerobic end products results in a shift from PK to PEPCK activity, due to nonoverlapping $\mathrm{pH}$ profiles of these two enzymes. The possibility of such a regulation in $F$. hepatica will be shown.

Preliminary results had shown the presence of malic enzyme (ME; EC 1.1.1.40) in the juvenile liver fluke [2]. If this $\mathrm{ME}$ is present in the cytosol and if it is active both in the carboxylating and decarboxylating direction, an interconversion of cytosolic malate and pyruvate can occur. In that case, the production of each of these cytosolic products need not correlate with the activities of PK and PEPCK. We, therefore, investigated whether the ratio of PK and PEPCK activities has any effect on the pattern of end products of glucose catabolism, in intact juveniles and adults. The acetate excreted by the worms during incubations in the presence of $\left[6-{ }^{14} \mathrm{C}\right]$ glucose was isolated, and the distribution of label between its carbon atoms was analysed to study the pathways of acetate formation in adult and juveniles.

During the development of the liver fluke in the final host, a transition occurs in the mitochondria from carbon dioxide production in the Krebs cycle to the formation of propionate and acetate [1]. This mitochondrial transition was also studied.

\section{Materials and Methods}

Parasite preparations. Juvenile $F$. hepatica were obtained by our previously described method for the in vitro excystment of metacercariae and subsequent isolation of juvenile liver flukes [9].

Liver flukes of 12,25 and 52 days old were isolated as described earlier $[1,3]$.
Adult $F$. hepatica were obtained from cows and sheep at a local slaughterhouse. Before use they were kept overnight at $38^{\circ} \mathrm{C}$ in a buffer ( $\mathrm{pH} 7.3$ ) containing $39 \mathrm{mM} \mathrm{NaHCO}, 78 \mathrm{mM} \mathrm{NaCl}, 5.4$ $\mathrm{mM} \mathrm{KCl}, 1 \mathrm{mM} \mathrm{NaH} \mathrm{PO}_{4}, 0.8 \mathrm{mM} \mathrm{MgSO}_{4}, 1.8$ $\mathrm{mM} \mathrm{CaCl}{ }_{2}, 11 \mathrm{mM}$ glucose, $12.5 \mathrm{mM} N$-tris (hydroxymethyl)--methyl-2-;aminoethanesulfonic acid (TES), $12.5 \mathrm{mM}$ ( $N$-morpholino)ethanesulfonic acid (MES), streptomycin (75 $\mathrm{mg} \mathrm{l}^{-1}$ ) and penicillin (75 $\mathrm{IU} \mathrm{m} \mathrm{ml}^{-1}$ ). This overnight maintenance is standard procedure to clean the intestines of the flukes, and does not lead to any physiological deterioration [10].

Cytosolic and mitochondrial preparations were obtained by treatment of juveniles (intact) or adults (cut with scissors) with a Potter-Elvehjem homogenizer at $0^{\circ} \mathrm{C}$ in a medium containing 250 $\mathrm{mM}$ sucrose and $10 \mathrm{mM}$ Tris ( $\mathrm{pH} \mathrm{7.4)}$. After centrifugation $\left(4^{\circ} \mathrm{C}\right)$ for $20 \mathrm{~min}$ at $700 \times \mathrm{g}$, the supernatant was centrifuged for $30 \mathrm{~min}$ at $48000 \times$ $g$. The supernatant of the second centrifugation was used as cytosolic fraction. The pellet was washed once, recentrifuged and resuspended in the same medium (mitochondrial fraction). In this fraction lactate dehydrogenase (LDH; EC 1.1.1.27) activity could not be detected $(<<1 \%$ of the supernatant).

Homogenates in $250 \mathrm{mM}$ sucrose, $50 \mathrm{mM}$ Tris (pH 7.4) were prepared with a Potter-Elvehjem homogenizer at $0^{\circ} \mathrm{C}$. After centrifugation $\left(4^{\circ} \mathrm{C}\right)$ for $30 \mathrm{~min}$ at $700 \times g$ to remove the debris, Triton $\mathrm{X}-100$ (final concentration $0.1 \%, \mathrm{v} / \mathrm{v}$ ) was added to the supernatant.

Incubations of intact $F$. hepatica. Aerobic and anaerobic incubations of intact $F$. hepatica with radioactively labelled glucose and the analysis of the excreted end products were carried out as described earlier [2] except that in the experiments presented in this paper $\mathrm{D}-\left[6^{-14} \mathrm{C}\right]$ glucose was used, and $25 \mathrm{mM} \mathrm{NaCl}$ in the incubation buffer was replaced by $12.5 \mathrm{mM}$ MES and $12.5 \mathrm{mM}$ TES. Adult flukes were preincubated for $2 \mathrm{~h}$ at the $\mathrm{pH}$ of the final incubation.

Incubations of homogenates. Homogenates were incubated in a final volume of $0.12 \mathrm{ml}$ for 5,10 or $15 \mathrm{~min}$ at $25^{\circ} \mathrm{C}$ in the presence of $0.1 \mathrm{mM}\left[1-{ }^{14} \mathrm{C}\right]$ acetyl-coenzyme A (AcCoA) $\left(33 \mathrm{mCi} \mathrm{mmol}^{-1}\right)$, 
$5 \mathrm{mM}$ oxaloacetate, $5 \mathrm{mM}$ succinate, $30 \mathrm{mM}$ glucose, $0.5 \mathrm{mM}$ ADP, $11 \mathrm{U}$ hexokinase, $15 \mathrm{mM}$ $\mathrm{KCl}, 2 \mathrm{mM}$ EDTA, $5 \mathrm{mM} \mathrm{MgCl}_{2}, 15 \mathrm{mM}$ $\mathrm{KH}_{2} \mathrm{PO}_{4}$ and $50 \mathrm{mM}$ Tris, $\mathrm{pH}$ 7.4. The incubations were terminated by the addition of $10 \mu \mathrm{l} 0.5$ $\mathrm{M} \mathrm{HCl}$ and immediate freezing in acetone/solid $\mathrm{CO}_{2}$. The end products were analysed by anionexchange chromatography on a Biorad AG 1-X8, 100-200 mesh column $(h=15 \mathrm{~cm}$, diam. $=0.3$ $\mathrm{cm}$ ) in chloride form. The column was eluted with $15 \mathrm{ml} 0.2 \mathrm{M} \mathrm{NaCl}$ and $25 \mathrm{ml} 0.3 \mathrm{M} \mathrm{NaCl}$. Linearity of the end-product formation with time and homogenate concentration was checked.

\section{Enzyme activities.}

Pyruvate kinase and phosphoenolpyruvate carboxykinase. It was found at an early stage in this investigation that the usual assays for the activities of PK and PEPCK do not give reliable results with homogenates of the liver fluke. In these spectrophotometric assays the activities of $\mathrm{PK}$ and PEPCK are differentiated by adding either LDH and ADP (for PK) or malate dehydrogenase (MDH; EC 1.1.1.37), IDP and bicarbonate (for PEPCK) to the assay medium. With crude $F$. hepatica preparations the two enzyme assays will interfere because: (1) these preparations contain endogenous $\mathrm{LDH}$ and $\mathrm{MDH}$; (2) the specificity for nucleoside diphosphate of PK and PEPCK is not strict; (3) bicarbonate is always present unless very strict precautions are taken. This interference was corrected for by determining the ratio of the amounts of radioactive enzyme products (lactate and malate), formed from $\left[1-{ }^{14} \mathrm{C}\right]$ PEP during the spectrophotometric assays. This cumbersome method was especially necessary for PK measurements in adult liver flukes, in which case interference by PEPCK and MDH contributed up to $50 \%$ of the measured NADH disappearance. PK and PEPCK activities were determined in the absence of known modulators of these activities [11].

PEPCK activity was assayed spectrophotometrically on an Aminco DW-2a at $25^{\circ} \mathrm{C}$. The assay $(1.1 \mathrm{ml})$ contained: $100 \mathrm{mM}$ MES, $100 \mathrm{mM}$ TES, $1.25 \mathrm{mM} \mathrm{MnCl}{ }_{2}, 0.5 \mathrm{mM}$ NADH, $3.1 \mathrm{mM}$ IDP, $10 \mathrm{U} \mathrm{MDH}, 12.5 \mathrm{mM} \mathrm{NaHCO}$ and $3.1 \mathrm{mM}$ [1-14 $\mathrm{C}]$ PEP $\left(0.6-1.2 \mathrm{mCi} \mathrm{mmol}^{-1}\right)$. The reaction was stopped with $\mathrm{HClO}_{4}$ (final concentration 5\%, $v / v)$. Radioactive products were determined in the neutralized incubation mixture. Corrections for blank incubations were made both in the spectrophotometric and in the radioactive assay.

PK activity was determined according to the same principles as PEPCK. The assay contained: $100 \mathrm{mM}$ MES, $100 \mathrm{mM}$ TES, $5 \mathrm{mM} \mathrm{MnCl}_{2}, 0.5$ mM NADH, $0.5 \mathrm{mM}$ ADP, $100 \mathrm{mM} \mathrm{KCl}, 10 \mathrm{U}$ $\mathrm{LDH}$ and $3.1 \mathrm{mM}\left[1-{ }^{14} \mathrm{C}\right] \mathrm{PEP}(0.6-1.2 \mathrm{mCi}$ $\mathrm{mmol}^{-1}$ ).

Malic enzyme. ME activities were determined at $25^{\circ} \mathrm{C}$ both in the decarboxylating and in the carboxylating direction. Spectrophotometric measurements at $340 \mathrm{~nm}$ of ME activities in crude preparations of $F$. hepatica are hampered by the presence in these preparations of $\mathrm{MDH}$ and LDH. Therefore, radioactive methods were chosen.

The carboxylating activity was measured as the incorporation of label from $\left[{ }^{14} \mathrm{C}\right]$ bicarbonate. The assay $(0.5 \mathrm{ml})$ contained: $100 \mathrm{mM}$ MES, $100 \mathrm{mM}$ TES, $0.2 \mathrm{mM}$ NAD(P)H, $0.5 \mathrm{mM}$ pyruvate, 4 $\mathrm{mM} \mathrm{MnCl}$, and $25 \mathrm{mM} \mathrm{NaH}{ }^{14} \mathrm{CO}_{3}(4 \mathrm{mCi}$ $\left.\mathrm{mmol}^{-1}\right)$. The remaining ${ }^{14} \mathrm{CO}_{2}$ disappeared from the medium after the reaction was stopped with $85 \mu \mathrm{l} 6 \mathrm{M} \mathrm{HCl}$. Corrections for blank incubations were made and linearity of the reaction with time was checked.

The decarboxylating activity was measured as the formation of radioactive bicarbonate from [U$\left.{ }^{14} \mathrm{C}\right]$ malate. The assay $(0.5 \mathrm{ml})$ contained: $100 \mathrm{mM}$ MES, $100 \mathrm{mM}$ TES, $4 \mathrm{mM} \mathrm{MnCl}_{2}, 0.2 \mathrm{mM}$ $\mathrm{NAD}(\mathrm{P})^{+}$and $0.5 \mathrm{mM} \mathrm{L}-\left[\mathrm{U}-{ }^{14} \mathrm{C}\right]$ malate $(5 \mathrm{mCi}$ $\left.\mathrm{mmol}^{-1}\right)$. The reaction was stopped by the injection of $\mathrm{HClO}_{4}$ (final concentration $5 \%, \mathrm{v} / \mathrm{v}$ ) to the closed vessel after the addition of $4 \mu \mathrm{mol} \mathrm{Na}$ $\mathrm{HCO}_{3}$ as carrier. $\mathrm{CO}_{2}$ was trapped with $\mathrm{NaOH}$ in a removable centre well. Corrections for blank incubations were made and linearity of the reaction with time was checked. Anion-exchange chromatography confirmed that the end product was pyruvate and not propionate.

Assays. Radioactive products in the PK and PEPCK assays and the end products excreted during incubations of intact $F$. hepatica with [6${ }^{14} \mathrm{C}$ ]glucose were analysed in the neutralized incubation mixture by anion-exchange chromatography on a Biorad AG 1-X8, 100-200 mesh col- 
umn $(h=60 \mathrm{~cm}$, diam. $=1.1 \mathrm{~cm})$ in chloride form. The column was eluted with $200 \mathrm{ml} 5 \mathrm{mM}$ $\mathrm{HCl}, 130 \mathrm{ml} 0.2 \mathrm{M} \mathrm{NaCl}$ and $130 \mathrm{ml} 0.5 \mathrm{M} \mathrm{NaCl}$.

Acetic acid recovered from the column was degraded by the Schmidt reaction [12] in an apparatus described by Rabinowitz [13] after the addition of $0.1 \mathrm{mmol}$ of carrier acetate. Corrections for blank incubations were made. Possible crosscontamination between carbon atoms was determined with positionally labelled acetate. It was found to be less than $1 \%$.

Protein contents were determined by the Lowry method with bovine serum albumin as standard (after disruption of the adult worms by ultrasonic treatment).

\section{Results}

Pyruvate kinase and phosphoenolpyruvate carboxykinase activities. In Fig. 1 the $\mathrm{pH}$ profiles are shown of PK and PEPCK activities in cytosolic preparations of adult and juvenile $F$. hepatica. It can be seen that in both adult and juvenile the activity of PEPCK was much more dependent on the $\mathrm{pH}$ than the activity of $\mathrm{PK}$ was, which indicates that regulation by $\mathrm{pH}$ is possible.

Malic enzyme activities. The $\mathrm{pH}$ profiles of $\mathrm{ME}$ activities in both directions in the cytosolic and mitochondrial fraction of the adult are shown in

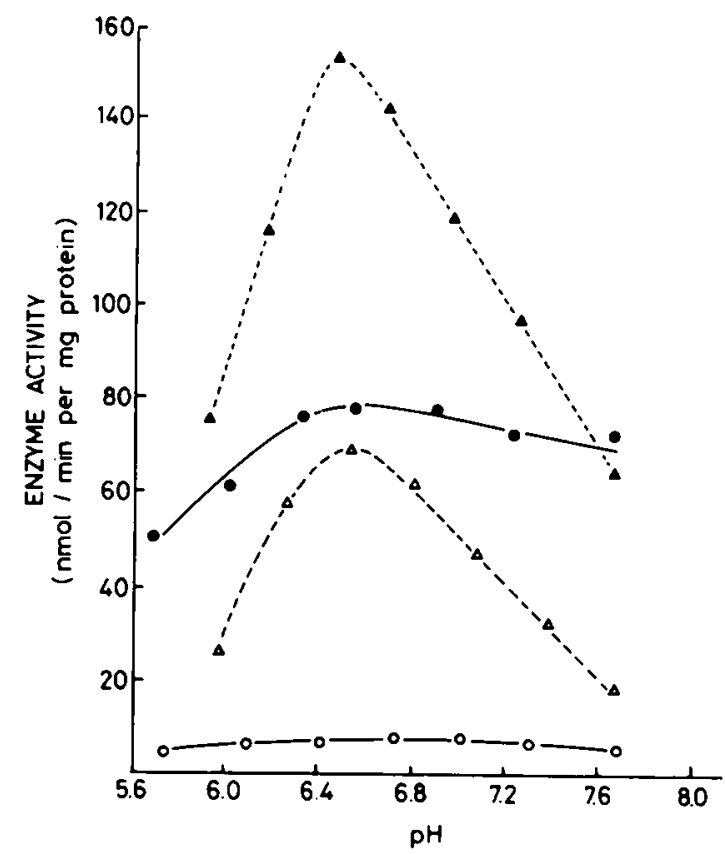

Fig. 1. pH profiles of the activities of PK $(O, 0)$ and PEPCK $(\triangle, \Delta)$ in cytosolic fractions of adult $(O, \Delta)$ and freshly excysted juvenile $(\mathbf{O}, \Delta) F$. hepatica.

Fig. 2. These activities were determined with $\mathrm{NADP}(\mathrm{H})$ as coenzyme. In the mitochondrial fraction the use of $\mathrm{NAD}(\mathrm{H})$ resulted in at most $1 \%$ of the enzyme activity measured with $\operatorname{NADP}(\mathrm{H})$. The cytosolic activity with $\mathrm{NAD}(\mathrm{H})$
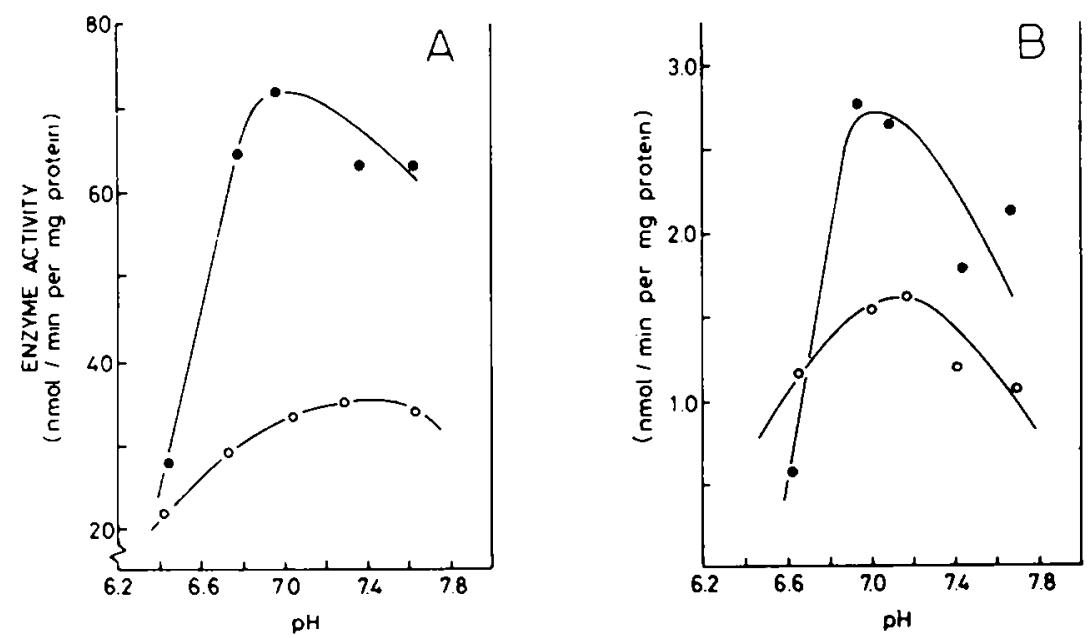

Fig. 2. $\mathrm{pH}$ profiles of the activity of NADP-dependent ME in cytosolic $(O)$ and mitochondrial $(O)$ fractions of adult $F$. hepatica. The reactions were measured in the decarboxylating (panel $A$ ) and carboxylating (panel $B$ ) directions. 
TABLE I

NADP-dependent malic enzyme activities in freshly excysted juvenile $F$. hepatica

\begin{tabular}{|c|c|c|}
\hline Direction & Fraction & $\begin{array}{l}\text { Activity at pH } 7.4^{\mathrm{a}} \\
\left(\mathrm{nmol} \mathrm{min}^{-1}(\mathrm{mg}\right. \\
\left.\text { protein })^{-1}\right)\end{array}$ \\
\hline carboxylating & $\begin{array}{l}\text { cytosol } \\
\text { mitochondria }\end{array}$ & $\begin{array}{l}0.24 \\
0.21 \\
1.85 \\
2.27\end{array}$ \\
\hline decarboxylating & $\begin{array}{l}\text { cytosol } \\
\text { mitochondria }\end{array}$ & $\begin{array}{r}0.49 \\
0.47 \\
10.18 \\
10.05\end{array}$ \\
\hline
\end{tabular}

- Results of separate determinations are presented.

was only about $25 \%$ and $4 \%$ of the activity with NADP $(\mathrm{H})$ for the carboxylating and decarboxylating activities, respectively. This preference for NADP is in agreement with an earlier preliminary report [14].

Owing to the limited number of juvenile parasites available, in the cytosolic and mitochondrial fractions of juveniles only the activities at $\mathrm{pH}$ 7.4 with $\mathrm{NADP}(\mathrm{H})$ as coenzyme were determined. These results are presented in Table I. In the presence of $1 \mathrm{mM} \mathrm{KCN}, \mathrm{ME}$ activity with $\operatorname{NADP}(\mathbf{H})$ in the carboxylating and decarboxylating direction was found to be inhibited for about 80 and $55 \%$, respectively, both in the mitochondrial and cytosolic fractions of adult and juvenile liver flukes.

The results demonstrate that a cyanide-sensitive, NADP-linked ME was present in the cytosol and the mitochondria of both adults and juveniles.

Incubations of intact juveniles and adults at different $p H$ values. The main radioactive end products of the breakdown of $\left[6^{-14} \mathrm{C}\right]$ glucose by intact juvenile and adult $F$. hepatica were analysed. In Table II their amounts are shown, expressed as percentages of the total amount of these products. The external $\mathrm{pH}$ had no significant effect on the degradation pattern (Table $\mathrm{II}$ ) nor on the rate of formation of the end products (not shown).

Pathways of acetate formation. The degradation of $\left[6-{ }^{14} \mathrm{C}\right]$ glucose via the Embden-Meyerhof-
Parnas pathway leads to the formation of [3${ }^{14}$ C]PEP. In Fig. 3 it is shown that only [2$\left.{ }^{14} \mathrm{C}\right]$ acetate is produced when $\left[3-{ }^{14} \mathrm{C}\right] \mathrm{PEP}$ is metabolized by PK and degraded directly to acetate via pyruvate and $\mathrm{AcCoA}$ (pathway 1). The same result is obtained when $\left[3-{ }^{14} \mathrm{C}\right] \mathrm{PEP}$ is metabolized by PEPCK and degraded via oxaloacetate, cytosolic malate, pyruvate and AcCoA (pathway $2)$. When $\left[3-{ }^{14} \mathrm{C}\right] \mathrm{PEP}$ is degraded via intramitochondrial malate, both $\left[1{ }^{14} \mathrm{C}\right]$ acetate and $[2$ ${ }^{14} \mathrm{C}$ Jacetate will be produced, because of the fumarate hydratase activity in the mitochondria. If malate fully equilibrates with fumarate it will lead to the production of equal amounts of [1$\left.{ }^{14} \mathrm{C}\right]$ acetate and $\left[2-{ }^{14} \mathrm{C}\right]$ acetate. After earlier reports that fumarate hydratase in $F$. hepatica is located in the cytosol, our observation that it has a mitochondrial localisation is now generally accepted [11].

The distribution of label between the carbon atoms of the acetate, excreted in the incubations

\section{TABLE II}

Effect of the $\mathrm{pH}$ on glucose metabolism by intact $F$. hepatica

\begin{tabular}{|c|c|c|c|c|}
\hline \multirow[t]{2}{*}{ Flukes } & \multirow[t]{2}{*}{$\mathrm{pH}$} & \multicolumn{3}{|c|}{$\begin{array}{l}\text { Product formation } \\
\text { (\% of glucose broken down })^{b}\end{array}$} \\
\hline & & $\mathrm{CO}_{2}$ & acetate & $\begin{array}{l}\text { propionate } \\
+ \text { lactate }^{c}\end{array}$ \\
\hline \multirow[t]{2}{*}{ juvenile } & 6.0 & 86 & 3 & 11 \\
\hline & & 88 & 5 & 8 \\
\hline \multirow[t]{2}{*}{ juvenile } & 7.4 & 89 & 5 & 5 \\
\hline & & 91 & 9 & n.d. ${ }^{d}$ \\
\hline \multirow[t]{2}{*}{ adult } & 6.0 & 6 & 27 & 67 \\
\hline & & 8 & 27 & 66 \\
\hline \multirow[t]{2}{*}{ adult } & 7.4 & 7 & 27 & 66 \\
\hline & & 7 & 33 & 60 \\
\hline
\end{tabular}

" The adult flukes (about $50 \mathrm{mg}$ protein per Erlenmeyer flask) were incubated aerobically for $1 \mathrm{~h}$ and the freshly excysted juveniles (about $1.8 \mathrm{mg}$ protein per Erlenmeyer flask) for 6 $h$. The excreted radioactive end products in the fluke-free medium were analysed and the amounts were corrected for blank incubations. Results of separate incubations are presented.

- The amount of glucose broken down in each incubation in the formation of $\mathrm{CO}_{2}$, acetate, propionate and lactate was calculated and put at $100 \%$.

The amount of lactate produced was not sufficient to permit a separate determination.

${ }^{\mathrm{d}}$ n.d. = not detectable. 


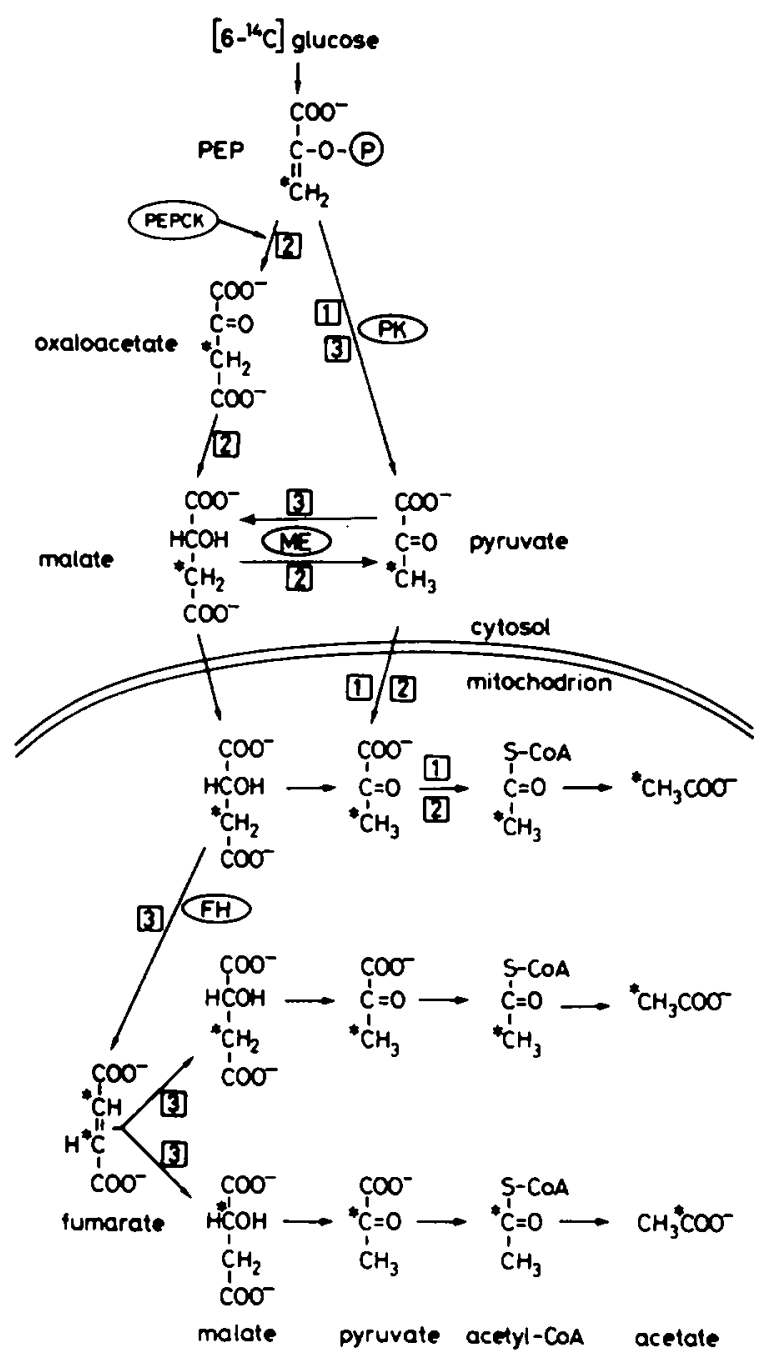

Fig. 3. Pathways of acetate formation from $\left[6-{ }^{14} \mathrm{C}\right]$ glucose by F. hepatica.

with adult $F$. hepatica shown in Table II, is reported in Table III. The distribution of the label between the 1 and 2 position was about 40 and $60 \%$, respectively. This means that $80 \%$ of the acetate was formed via fumarate. Either all acetate was produced via intramitochondrial malate, the fumarate hydratase reaction not being in equilibrium, or about $20 \%$ of the acetate was produced via pathways 1 and/or 2 with the fumarate hydratase reaction completely equilibrated. A combination of both interpretations, i.e. an incomplete equilibrium and a partial utilization of the pathways 1 and 2 , is also possible.
TABLE III

Distribution of label in acetate, excreted by adult $F$. hepatica during aerobic incubations with $\left[6-{ }^{14} \mathrm{C}\right]$ glucose

\begin{tabular}{lll}
\hline $\mathrm{pH}$ & \multicolumn{2}{l}{ Distribution of label (\% of the total) } \\
\cline { 2 - 3 } & $\mathrm{CH}_{3}$ & $\mathrm{COO}^{-}$ \\
\hline 6.0 & 57 & 43 \\
& 61 & 39 \\
7.4 & 58 & 42 \\
& 60 & 40 \\
\hline
\end{tabular}

a The acetate was isolated from the incubations shown in Table II. Results of separate incubations are shown.

The results of Table III also demonstrate that the $\mathrm{pH}$ of the incubation had no influence on the distribution of the label in acetate.

The distribution of the label in acetate, excreted by juveniles during aerobic and anaerobic incubations at $\mathrm{pH} 7.4$ in the presence of [6${ }^{14} \mathrm{Clglucose}$, is reported in Table IV. The distribution of label between the 1 and 2 position of about 25 and $75 \%$ in the aerobic incubations shows that $50 \%$ of the acetate was formed via fumarate. This means that glucose is not degraded by the juvenile liver fluke exclusively via pathway 1. The distribution of label in acetate, excreted by juveniles during anaerobic incubations, was not the same as that in the acetate excreted by adults. This indicates that the utilization of the pathways of acetate production in anaerobic juveniles and adults was not the same.

The conversion of acetyl-CoA into citrate and acetate. In aerobic conditions, acetyl-CoA is distributed between the Krebs cycle and acetate for-

\section{TABLE IV}

Distribution of label in acetate, excreted by freshly excysted juvenile $F$. hepatica during incubations with $\left[6-{ }^{14} \mathrm{C}\right]$ glucose

\begin{tabular}{lll}
\hline Incubation conditions & \multicolumn{2}{l}{ Distribution of label (\% of the total) } \\
\cline { 2 - 3 } & $\mathrm{CH}_{3}$ & $\mathrm{COO}^{-}$ \\
\hline aerobic & 75 & 25 \\
& 78 & 22 \\
anaerobic & 73 & 27 \\
& 69 & 31 \\
\hline
\end{tabular}

Results of separate incubations (at pH 7.4) are presented 


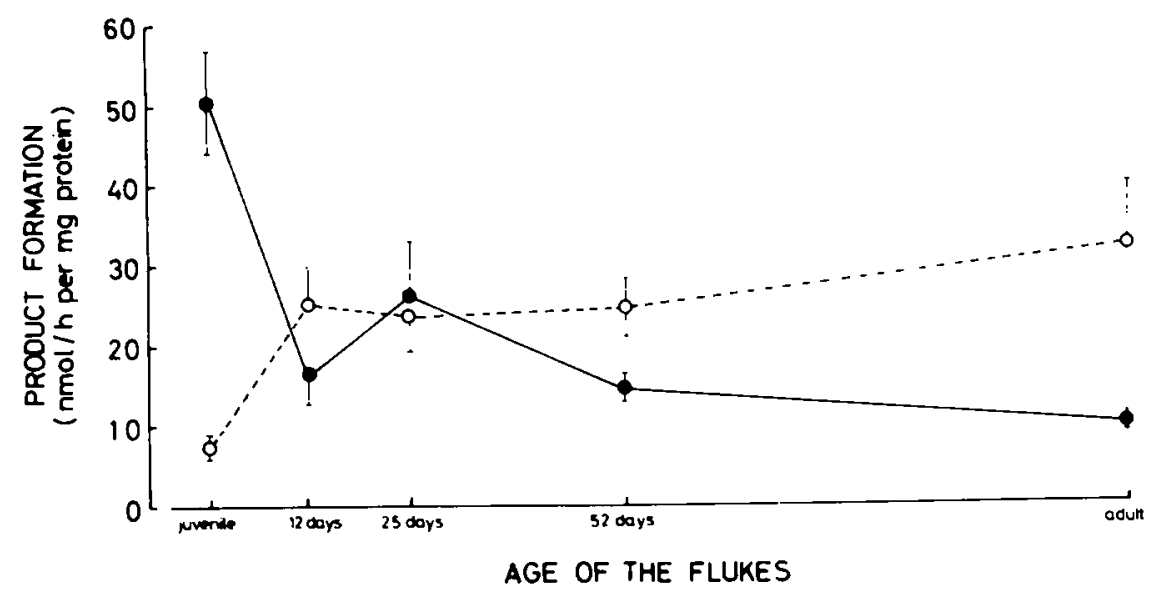

Fig. 4. The production of labelled citrate $(O)$ and acetate $(O)$ from $\left[1-{ }^{14} \mathrm{C}\right] \mathrm{AcC} \mathrm{CA}$ by $F$. hepatica of different ages. Juvenile stands, as usual, for 0-day freshly excysted flukes. Each value is the mean of at least 5 incubations \pm SD.

mation. This distribution depends on the relative activities of citrate synthase and of the enzyme(s) converting AcCoA into acetate. Therefore, we investigated these activities during the development of $F$. hepatica. Due to the limited amount of material available, homogenates instead of mitochondrial preparations were used for this study.

Homogenates of several stages of $F$. hepatica were incubated with $\left[1-{ }^{14} \mathrm{C}\right] \mathrm{AcCoA}$ and the production of labelled citrate and acetate was measured. The results shown in Fig. 4 demonstrate that citrate formation decreased whereas the production of acetate increased during the development of the liver fluke. The ratio of citrate to acetate produced changed more than 20 -fold.

\section{Discussion}

The cytosolic degradation of glucose via PK, as compared to that via PEPCK, was more important in juvenile $F$. hepatica than in the adult, as can be concluded from the following results: (1) The PK/PEPCK ratio in the cytosol of the juveniles was much higher than in the cytosol of the adults (Fig. 1). (2) In the presence of cyanide which inhibits $\mathrm{ME}$, lactate accumulated in aerobic incubations of juveniles [2], but not of adults. (3) The juvenile produced acetate to a larger extent via cytosolic pyruvate (pathways 1 and 2 in Fig. 3) than did the adult. This conclusion is correct in the most likely case that intramitochon- drial malate and fumarate fully equilibrate. It is also correct if the equilibrium between these intermediates, though not complete, occurs to the same extent in the juvenile and in the adult.

Label in the carboxyl group of acetate does not necessarily imply that PEPCK activity is involved. It is possible that PEP is metabolized by PK via pathway 3 in Fig. 3. Therefore, the distribution of label in acetate is not an accurate measure of the in vivo ratio of PK and PEPCK activity. It only gives an indication of the maximal activity of the pathways 1 plus 2 . Nevertheless, the high percentage of label in the carboxyl group of acetate indicates that the idea of one simple pathway in the juvenile for aerobic glucose breakdown via pyruvate [2] has to be rejected.

Although in the adult the degradation of glucose via PEPCK was more important than the degradation via PK, malate was not the only end product of the cytosolic degradation: pyruvate was probably also a cytosolic end product and a substrate for further mitochondrial breakdown. This can be concluded from the distribution of label in the acetate excreted by adult liver flukes (Table III), indicating that $20 \%$ of the acetate was produced from cytosolic pyruvate, if it is assumed that the equilibration of malate and fumarate was instantaneous.

During the development of $F$. hepatica in the final host, the limited availability of oxygen grad- 
ually forces the liver fluke to an anaerobic energy metabolism. This lack of oxygen first occurs, due to the limited diffusion of oxygen, in the innermost tissues of the parasite and is caused by its increase in size [1]. After arrival in the bile ducts, almost the entire fluke will be anaerobic because the oxygen content of bile is very low.

When the parasite is forced to anaerobic functioning, glucose degradation will have to be in redox balance. The juvenile will then produce propionate and acetate in a ratio of $2: 1$, just like the adult [2]. However, anaerobiosis in the juvenile did not immediately lead to the adult type of cytosolic metabolism, as can be concluded from a comparison of Tables III and IV.

The end products of glucose breakdown by $F$. hepatica were not dependent on the PK/PEPCK ratio, as can be concluded from Table II. The two $\mathrm{pH}$ values used in the experiments in Table II were selected to give the maximal difference in PK/PEPCK ratio. ${ }^{31} \mathrm{P}$ nuclear magnetic resonance $\left({ }^{31} \mathrm{P}-\mathrm{NMR}\right)$ experiments had shown that in adult liver flukes an external $\mathrm{pH}$ of 6.0 results in an intracellular $\mathrm{pH}$ of 6.5 [10], the $\mathrm{pH}$ optimum of PEPCK.

The observations showing (1) that probably not all the acetate produced by the adult was formed via malate, (2) that a change in the PK/PEPCK ratio in the adult had no influence on the endproduct pattern and (3) that the anaerobically functioning juvenile produced propionate and acetate via different pathways from those in the adult, support our hypothesis [2] that malate is not the only mitochondrial substrate for the wellknown anaerobic production of propionate and acetate. The presence of ME in the mitochondria of adults and juveniles, acting both in the carboxylating and decarboxylating direction (Fig. 2 and Table I), enables the mitochondria to dismutate both malate and pyruvate to propionate and acetate. Most likely, a mixture of pyruvate and malate will be the mitochondrial substrate for the production of acetate and propionate. Pyruvate dismutation will be important in the juvenile, whereas in the adult malate will be the major, but not the exclusive mitochondrial substrate.

If pyruvate instead of malate is the substrate for anaerobically functioning mitochondria, one reducing equivalent (NADH) has to be shuttled into the mitochondria for every molecule of pyruvate utilized. The presence of such shuttle mechanisms in adult $F$. hepatica has been demonstrated [6]. Pyruvate dismutation (combined with the shuttle into the mitochondria of an equimolar amount of cytosolic NADH) will result in the same end products as malate dismutation: propionate and acetate will be formed in a molar ratio of 2:1. Recently, Kane and Bryant [15] also provided evidence that in adult $F$. hepatica, at least under certain conditions, pyruvate is a cytosolic end product which enters the mitochondrion and participates in a dismutation reaction.

When $F$. hepatica grows, a lack of oxygen forces the worm to produce propionate and acetate. These acidic end products will lower the cytosolic $\mathrm{pH}$. After arrival in the bile ducts the excretion of these end products together with the restricted flow of bile and the limited buffer capacity will acidify the environment of the fluke and, as ${ }^{31} \mathrm{P}$ NMR studies have shown [10], this will contribute to the decrease of the intracellular $\mathrm{pH}$. This lower internal $\mathrm{pH}$ will favour a partitioning of the flux towards PEPCK at the PK/PEPCK branchpoint (Fig. 1). This $\mathrm{pH}$ effect will be paralleled by the proposed effects of the high concentration of bicarbonate in the bile: inhibition of PK activity and stimulation of PEPCK activity [7].

This proposed short-term regulation will be followed by a more permanent change: PEPCK will become the main branch, due to a strongly decreased PK activity in the adult (Fig. 1).

Isolated mitochondria from the juvenile liver fluke can degrade both pyruvate and malate via the Krebs cycle, but also via the dismutation reactions [Tielens, A.G.M. (1982) The energy metabolism of the juvenile liver fluke, Fasciola hepatica, during its development in the vertebrate host. Ph. D. Thesis, Utrecht, The Netherlands]. On the other hand, the same studies showed that isolated mitochondria from the adult possess only the dismutation possibility, but again both pyruvate and malate can act as substrates. Since the adult-type mitochondria have apparently lost the Krebs-cycle activity, a mitochondrial change will have to occur as well during the development of $F$. hepatica.

The entrance of AcCoA into the Krebs cycle is the most obvious point to exert control over the 
two pathways and Fig. 4 shows that the mitochondria at the AcCoA branchpoint indeed gradually switched from citrate to acetate formation. It is known that the Krebs-cycle activity per mg protein decreases during the entire development of $F$. hepatica in the vertebrate host. On the other hand, the Krebs-cycle activity per fluke actually increases during this development [1]. It has been shown that during growth of the fluke probably only a thin outer layer of the parasite retains its Krebs-cycle activity and, starting from its innermost center, the parasite becomes more and more anaerobic [1]. Therefore, in our opinion the observed slow transition at the AcCoA branchpoint (Fig. 4) does not represent a gradual switch of each individual mitochondrion, but reflects the average of the entire population of mitochondria.

\section{References}

1 Tielens, A.G.M., van den Heuvel, J.M. and van den Bergh, S.G. (1984) The energy metabolism of Fasciola hepatica during its development in the final host. Mol. Biochem. Parasitol. 13, 301-307.

2 Tielens, A.G.M., van der Meer, P. and van den Bergh, S.G. (1981) The aerobic energy metabolism of the juvenile Fasciola hepatica. Mol. Biochem. Parasitol. 3, 205-214.

3 Tielens, A.G.M., van den Heuvel, J.M. and van den Bergh, S.G. (1982) Changes in the energy metabolism of the juvenile Fasciola hepatica during its development in the liver parenchyma. Mol. Biochem. Parasitol. 6, 277-286.

4 Lahoud, H., Prichard, R.K., McManus, W.R. and Schofield, P.J. (1971) Volatile fatty acid production by the adult liver fluke Fasciola hepatica. Comp. Biochem. Physiol. 38B, 379-391.

5 Prichard, R. and Schofield, P. (1968) The metabolism of phosphoenolpyruvate and pyruvate in the adult liver fluke Fasciola hepatica. Biochim. Biophys. Acta 170, 63-76.

6 Prichard, R.K. (1976) Regulation of pyruvate kinase and phosphoenolpyruvate carboxykinase in adult Fasciola hepatica (trematoda). Int. J. Parasitol. 6, 227-233.

7 Behm, C.A. and Bryant, C. (1980) Regulatory properties of a partially purified preparation of pyruvate kinase from Fasciola hepatica. Int. J. Parasitol. 10, 107-114.
In mitochondria of the outer layer citrate-synthase activity will be predominant, whereas others (more innerwards the fluke) have lost their Krebs-cycle activity and have switched to the production of acetate (and propionate).

\section{Acknowledgements}

The authors thank Dr. H.J. Over and the Parasitology Department of the Central Veterinary Institute (Lelystad) for the generous supply of metacercariae. This work was supported by the Netherlands Foundation for Chemical Research (S.O.N.) with financial aid from the Netherlands Organization for the Advancement of Pure Research (Z.W.O.).

8 De Zwaan, A. (1977) Anaerobic energy metabolism in bivalve molluscs. Oceanogr. Mar. Biol. Annu. Rev. 15, 103-187.

9 Tielens, A.G.M., van der Meer, P. and van den Bergh, S.G. (1981) Fasciola hepatica: Simple, large-scale, in vitro excystment of metacercariae and subsequent isolation of juvenile liver flukes. Exp. Parasitol. 51, \&-12.

10 Tielens, A.G.M., Nicolay, K. and van den Bergh, S.G. (1982) ${ }^{31}$ P-NMR studies of $\mathrm{pH}$ homeostasis in intact adult Fasciola hepatica. Mol. Biochem. Parasitol. 6, 175-180.

11 Lloyd, G.M. (1986) Energy metabolism and its regulation in the adult liver fluke Fasciola hepatica. Parasitology 93, 217-248.

12 Sakami, W. (1955) Handbook of Isotope Tracer Methods, pp. 63-69, Western Reserve University Press, Cleveland, $\mathrm{OH}$.

13 Rabinowitz, J.L. (1957) Apparatus for wet oxidation of organic samples and carbon dioxide trapping for subsequent radioactive assay. Anal. Chem. 29, 982-984

14 Prichard, R.K. (1978) The metabolic profile of adult Fas ciola hepatica obtained from rafoxanide-treated sheep. Parasitology 76, 277-288.

15 Kane, H.J. and Bryant, C. (1984) 3-Mercaptopicolinic acid and energy metabolism in the liver fluke, Fasciola hepatica. Int. J. Parasitol. 14, 383-389. 